\title{
On Microstructure and Corrosion Properties of Selective Laser Melted 316L Stainless Steel
}

\author{
Mostafa Kazemipour ${ }^{1 *}$, Ali Nasiri ${ }^{1}$ \\ ${ }^{1}$ Faculty of Engineering and Applied Science, Memorial \\ University of Newfoundland, St. John's, NL, Canada \\ *mkazemipour@mun.ca
}

\author{
Mohsen Mohammadi² \\ ${ }^{2}$ Marine Additive Manufacturing Centre of Excellence \\ (MAMCE), University of New Brunswick, Fredericton, NB, \\ Canada
}

\begin{abstract}
In this study, a laser additive manufacturing method, known as selective laser melting (SLM), was applied to produce cube blocks of 316L stainless steel. The microstructure and corrosion properties of the produced samples were analyzed using scanning electron microscopy, cyclic potentiodynamic polarization testing, and electrochemical impedance spectroscopy. The results were also compared with the properties of a conventional wrought 316L stainless steel sample. The microstructural studies showed that the SLM-manufactured samples have a regular network of melt pools containing austenite grains along with elongated or equiaxed cellular sub-grains. The potentiodynamic polarization results depicted that the SLM fabricated samples had higher positive pitting potential and a wider passivation range than those of the wrought sample, corresponding to their better corrosion resistance. However, the SLM fabricated samples showed a weaker re-passivation property, which possibly is attributed to the presence of preexisting porosities in the structure of the SLM sample formed during the fabrication process. The EIS data also confirmed a larger capacitive arc for the SLM fabricated samples than its wrought counterpart, indicating a higher charge transfer impedance and a better corrosion resistance.
\end{abstract}

Keywords: Selective laser melting, Additive manufacturing, $316 \mathrm{~L}$ Stainless steel, Microstructure, Corrosion properties

\section{INTRODUCTION}

Nowadays, innovative and advanced 3-dimentional printing, also named additive manufacturing (AM), as a bottom-up method, is rapidly growing and has drawn many attentions from both academia and industry due to its capabilities in the production of near-net shaped components. Comparing with conventional manufacturing processes, such as casting or forming, this technology provides many advantages including fabrication of metallic parts with more complex shapes, less time from design stage to manufacturing, no need to post processing, and lower wastage precursors. In this technology, without the usage of specialized molds or tools, in a single step process, 3D components are fabricated through layer-wise addition of melted/sintered precursors powder on the substrate or previous layers, based on their digitally defined Computer Aided Design (CAD) data [1-6]. In recent years, various laser-based additive manufacturing methods for fabrication of metallic components have been developed, such as laser engineered net shaping (Lenz), direct metal deposition (DMD), laser solid forming (LSF), direct laser fabrication (DLF), laser metal deposition shaping (LMDS), direct metal laser sintering (DMLS), and selective laser melting (SLM) [1,5,7].

316L austenite stainless steel (316L SS) with excellent corrosion resistivity, decent mechanical properties, and good weldability is widely used for various applications in many industries, such as oil and gas, marine, and biomedical sectors. Currently, 316L components are mainly produced using conventional manufacturing methods, which do not allow for the production of complex shapes and therefore, final parts need to be welded or machined, consequently both fabrication time and cost increase. Additive manufacturing has emerged as an appropriate solution to resolve this issue. Nevertheless, the components built through these techniques have different microstructures and properties than those fabricated through conventional methods, which makes it crucial to study and research their as-printed properties $[5,6,8]$. In spite of existing comprehensive works on investigating various properties of SLM fabricated parts, there is very limited literature on corrosion related characteristics and electrochemical properties of AM components [9]. In the present study, the microstructure and corrosion performance of a $316 \mathrm{~L}$ stainless steel (SS) produced through SLM technique were studied and the results were compared with a conventional wrought 316L SS.

\section{MATERIALS AND METHODS}

Several cube blocks of 316L SS with the edge length of 15 mm were printed through SLM technique using a Renishaw AM 250 3D printer machine. The SLM processing parameters included powder layer thickness of $40 \mu \mathrm{m}$, laser power of 180 Watt, hatch distance of $0.08 \mathrm{~mm}$, hatch offset of $0.18 \mathrm{~mm}$, exposure time of $65 \mu \mathrm{s}$, and the bed temperature of $80^{\circ} \mathrm{C}$. The precursor powder particle size for SLM was maximum $63 \mu \mathrm{m}$ in diameter. 
Table 1. Nominal chemical composition of the used wrought and SLM-316L SS (wt. \%)

\begin{tabular}{|c|c|c|c|c|c|c|c|c|c|}
\hline Material & $\mathbf{C}$ & $\mathbf{P}$ & $\mathbf{S i}$ & $\mathbf{N i}$ & $\mathbf{M n}$ & $\mathbf{S}$ & $\mathbf{C r}$ & $\mathbf{M o}$ & $\mathbf{F e}$ \\
\hline Wrought 316L SS & 0.017 & 0.032 & 0.540 & 10.090 & 1.570 & 0.025 & 16.890 & 2.040 & Bal. \\
\hline SLM-316L SS & 0.030 & 0.025 & 0.750 & 14.000 & 2.000 & 0.010 & 18.000 & 2.620 & Bal. \\
\hline
\end{tabular}

The chemical composition of SLM-316L SS and its wrought counterpart are presented in Table 1. To investigate the impact of the building direction, the SLM produced samples were cross sectioned both perpendicular and parallel to the building direction, provided the top and the side views, respectively. To study corrosion resistivity of the samples, Cyclic Potentiodynamic Polarization (CPP) and Electrochemical Impedance Spectroscopy (EIS) tests were carried out. Before the electrochemical testing, all samples were cold mounted into an epoxy resin to limit the exposed area of the sample to only one face, while a wire was connected to the back side of the sample through the resin, providing the electrical connection during the electrochemical tests. This was followed by standard grinding and polishing of the surface to a mirror-like surface finish. All the tests were performed using an IVIUM Potentiostat/Galvanostat instrument in a three electrodes cell system containing the sample as the working electrode, a platinum plate as the auxiliary electrode, and $\mathrm{Ag} / \mathrm{AgCl}$ as the reference electrode. In all experiments, aerated $3.5 \mathrm{wt} . \%$ $\mathrm{NaCl}$ solution at room temperature $\left(25 \pm 1{ }^{\circ} \mathrm{C}\right)$ was used as the electrolyte. Before every test, open circuit potential (OCP) was measured for $3600 \mathrm{~s}$ to ensure the samples reached to the stability. The CPP test was conducted at scan rate of $1 \mathrm{mV} / \mathrm{s}$, starting from $-0.2 \mathrm{~V}$ versus the OCP up to the vertex current of $10 \mathrm{~mA}$, in which the scanning direction was then reversed. The EIS test was performed in an AC current with the amplitude perturbation of $\pm 10 \mathrm{mV}$ with respect to the OCP in a frequency range from $10^{5} \mathrm{~Hz}$ to $10^{-2}$ $\mathrm{Hz}$ in the 3.5 wt. $\% \mathrm{NaCl}$ solution at $25{ }^{\circ} \mathrm{C}$. For microstructural study, the polished samples were electroetched in $20 \%$ Nitric acid solution at the voltage of $1.7 \mathrm{~V}$ for $15 \mathrm{~s}$.

\section{RESULTS AND DISCUSSION}

Fig. 1 shows the microstructures of electro-etched wrought and SLM-316L samples. It can be seen that the SLM sample possesses a woven network of well-defined melt pools (Fig.1 a-d). This special structure has been resulted from the scanning action of the laser beam, where the long axis of the elliptical shaped melt pools corresponds to the direction of the laser scan in the SLM process (Fig. 1a-top view). Fig. 1d shows the cross-section of the printed sample across the plane parallel to the building direction (side view), revealing overlapped melt pools with semi-circular shapes. Clearly, the side view (Fig. 1d) contains higher density of the melt pool boundaries than the top view (Fig. 1a). At higher magnification, the austenite grains were appeared inside each melt pool and in each of the grains, elongated or equiaxed cellular sub-grains structure were revealed (Fig. $1 \mathrm{a}, \mathrm{c})$. The size of the sub-grains is around $1 \mu \mathrm{m}$ in diameter. These microstructural features are ascribed to extremely rapid solidification rate of the process, which in turn induces the elemental segregation and enrichment of sub-grain boundaries [7]. Trelewicz et al. [7] have shown that because of Mo and $\mathrm{Cr}$ segregation along the cell boundaries of SLM-316L, the corrosion characteristics of the intercellular regions are different, associated with rapid solidification and non-equilibrium nature of the process. Consequently, when the surface was electro-etched, the cell boundaries were not corroded as severe as the interior of the cells, resulting in unveiling the sub-grain structure. As expected, the microstructure of the wrought sample (Fig. 1e) contains annealed equiaxed grains along with recrystallized regions formed during annealing.

The cyclic potentioadynamic polarization curves of the SLM (both top and side views) and wrought samples obtained in aerated 3.5 wt. $\% \mathrm{NaCl}$ solution at room temperature are presented in Fig. 2. Electrochemical corrosion parameters including corrosion potential ( $\left.\mathrm{E}_{\mathrm{Corr}}\right)$, corrosion current ( $\left.\mathrm{i}_{\text {Corr }}\right)$, pitting potential $\left(\mathrm{E}_{\mathrm{pit}}\right)$, defined as the inflection point in the anodic polarization curve, where the current density rapidly increases, and re-passivation potential $\left(\mathrm{E}_{\mathrm{rep}}\right)$, where the reverse scan intersects the forward scan, extracted from the CPP curves, are shown in Table 2. A combination of higher $\mathrm{E}_{\text {Corr }}$ and lower $i_{\text {Corr }}$ corresponds to a better corrosion performance. Comparing the corrosion data reveals that the top side of the SLM-sample has the highest corrosion resistance. All samples exhibited a clear passive region. Similarly, the top surface of the SLM sample possessed the widest passive range with the highest $\mathrm{E}_{\mathrm{pit}}$ contributing to a better corrosion properties of the sample. Using Tafel equation and tangent lines slopes on the cathodic and anodic regions of the curves, corrosion rates of the samples were derived that were found to be consistent with the above-mentioned results. In all samples, sharp fluctuations in current density can be seen in passive region showing the pitting initiation, so called metastable pitting. In fact, metastable pitting represents the start, growth and repassivation of a micro-pit on the surface of the samples. However, when the critical value of the potential is reached, the micro-pit can be transformed to a stable pit and then the passive layer on the surface is permanently ruined [10]. Comparing the $\mathrm{E}_{\text {rep }}$ of the samples, it is evidenced that SLM sample has weaker re-passivation property. 


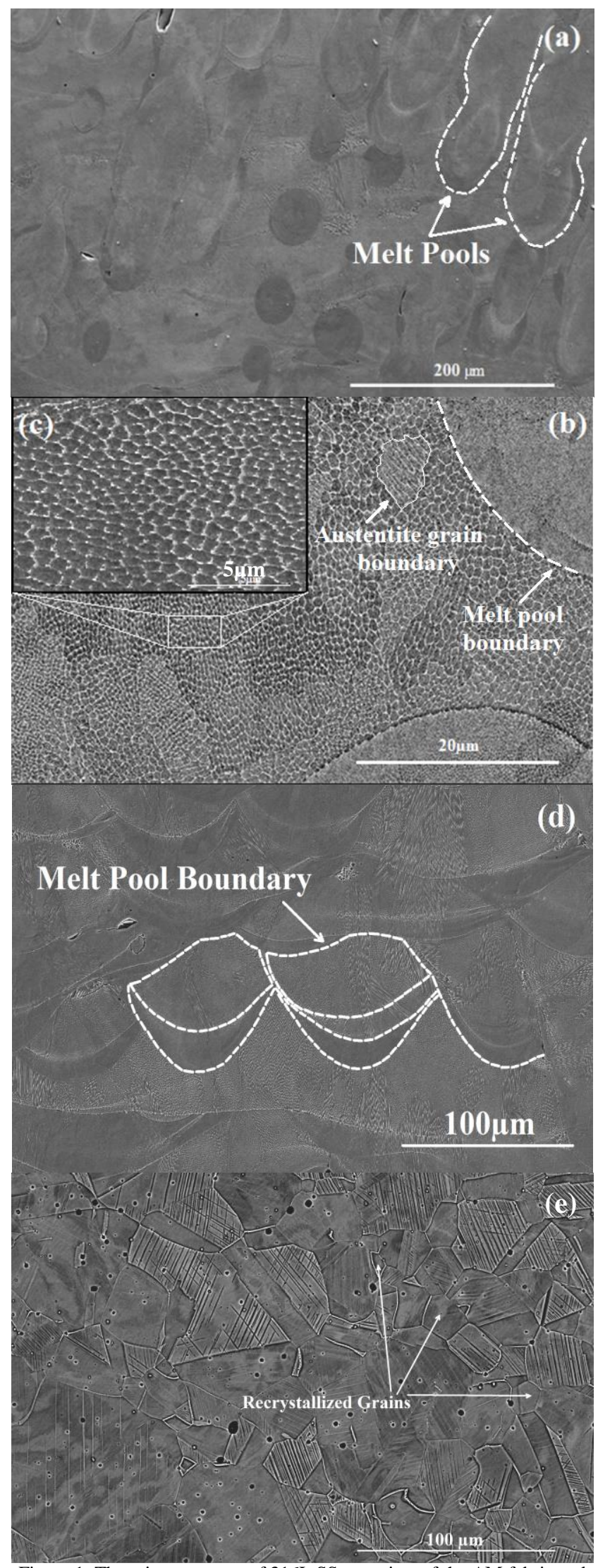

Figure 1. The microstructure of 316L SS: top view of the AM fabricated sample (a-c), side view of the AM fabricated sample (d), wrought sample (e).

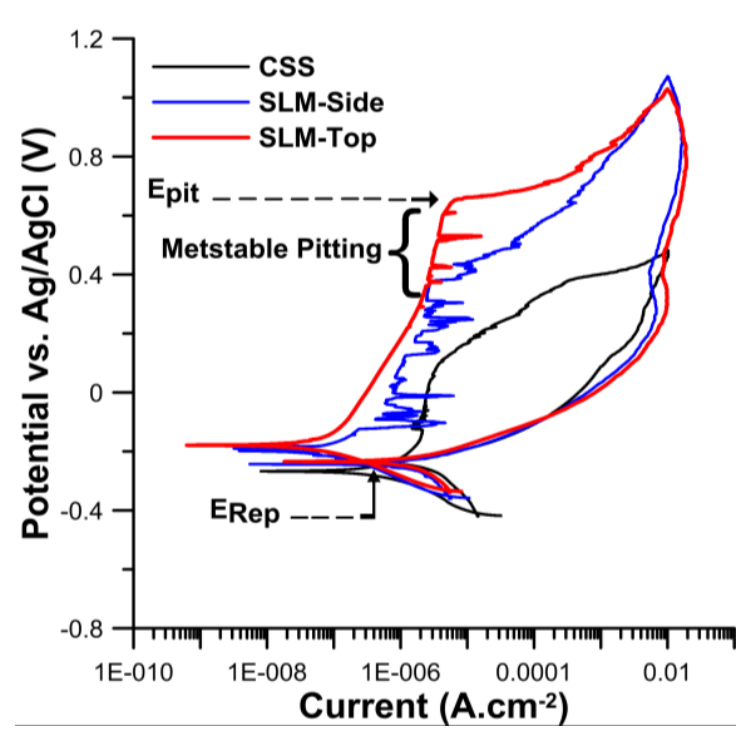

Figure 2. Cyclic potentiodynamic polarization curves of the studied samples.

No clear dependency so far has been reported between $E_{\text {Corr }}$, $\mathrm{i}_{\text {Corr, and }} \mathrm{E}_{\mathrm{pit}}$ of additively manufactured products with porosity level of the sample [11]. However, it has been shown that the amount of $\mathrm{E}_{\text {rep }}$ in additively manufactured products is dependent on their porosity level [11]. Therefore, the improved re-passivation behavior of the wrought sample can be justified if the porosity level of the sample is considered zero relative to the SLM sample containing numerous pre-existing porosities in its structure (see Fig. 1d). The SEM micrographs of the SLM samples after the CPP test are depicted in Fig. 3. It can be seen that there is no preferred position for pit formation on the surface and the specimen exhibits isolated corrosion pits.

Additional experiment on the corrosion behavior of the samples were done by EIS tests to investigate the protective nature of the formed passive film on the 316L SS surface. The Nyquist plots in Fig. 4 depict a single semi-circle capacitive arc trend that corresponds to double layer and passive film formation on the samples' surfaces. This indicates that the corrosion mechanism of all three samples were identical and typical of stainless steel material. The EIS data showed a larger capacitive arc, an indication of improved corrosion resistance, for the SLM samples (both top and side views) than that of the wrought $316 \mathrm{~L}$ SS. It confirms the aforementioned CPP results of the corrosion properties. Comparing the results of the top and side views of the SLM sample reveals that the top view is covered by a more protective passive layer that can be correlated to the lower density of the melt pool boundaries on this face than that on the side view.

\section{Conclusion}

In the present work, the corrosion properties of the selective laser melted 316L stainless steel and its wrought counterpart were studied. Microstructural analysis of the samples 
revealed that the SLM processed stainless steel contained very fine cellular sub-grain structure resulted from scanning action of the laser beam combined with rapid solidification of the melt pools, contributing to elemental segregation along the intercellular boundaries. Through electrochemical tests, it was found that SLM-316L SS has higher pitting resistance, lower corrosion rate, and more noble corrosion potential than those of the wrought sample. However, its repassivation potential was degraded, which was primarily attributed to the pre-existing porosities in its structure formed during the fabrication process.

Table2. Corrosion characteristics of the studies samples

\begin{tabular}{|c|c|c|c|c|c|c|}
\hline Sample & $\mathbf{i}_{\text {Corr }}\left(\boldsymbol{\mu A} \mathbf{A} \mathbf{c m}^{2}\right)$ & $\mathbf{E}_{\text {Corr }}(\mathbf{V})$ & $\mathbf{i}_{\text {Pitting }}\left(\boldsymbol{\mu A} \mathbf{A} / \mathbf{c m}^{2}\right)$ & $\mathbf{E}_{\text {Pitting }}(\mathbf{V})$ & Corr. Rate $(\mathbf{m m} / \mathbf{y})$ & $\mathbf{E}_{\text {Rep }}(\mathbf{V})$ \\
\hline Wrought SS & 1.7957 & -0.3 & 3.630 & 0.0922 & 0.01824 & -0.2258 \\
\hline SLM-SS-Top & 0.1788 & -0.1923 & 7.026 & 0.6542 & 0.002165 & -0.2316 \\
\hline SLM-SS-Side & 0.1843 & -0.2 & 2.723 & 0.3656 & 0.002059 & -0.2412 \\
\hline
\end{tabular}

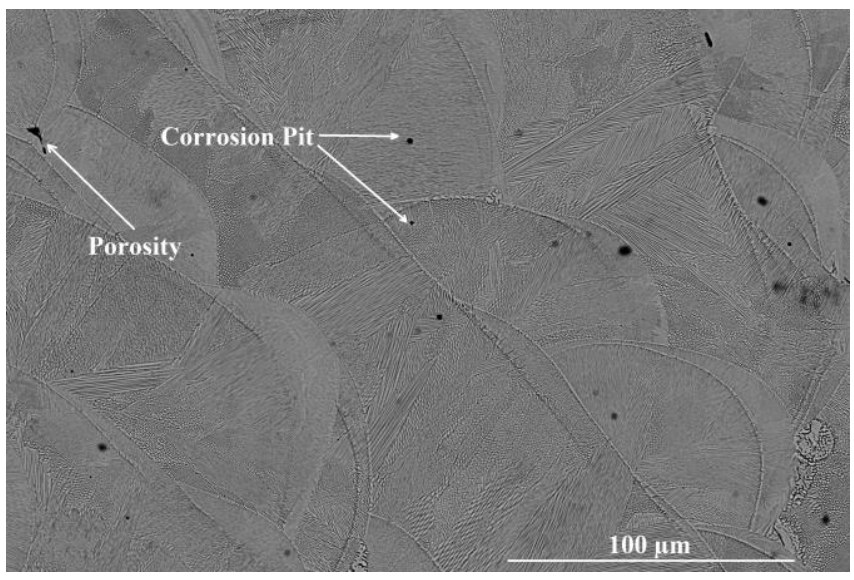

Figure 3. SEM micrograph of the AM sample after corrosion (side view).

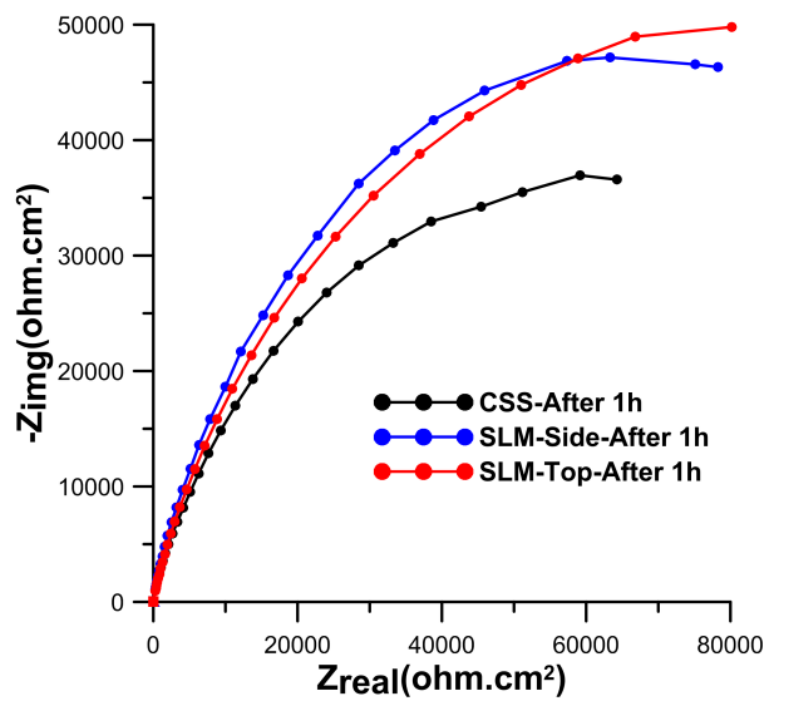

Figure 4. EIS measurement plots of the experimental samples.

\section{Acknowledgment}

The authors would like to thank the support of Natural Sciences and Engineering Research Council of Canada (NSERC) [grant number RGPIN-2017-04368], for sponsoring this work. M.M. would like to specially thank
NSERC [Grant number RGPIN-2016-04221] and New Brunswick Innovation Foundation (NBIF) [Grant number RIF2017-071] for providing enough funding to conduct this research work.

\section{References}

[1] M. Zietala, T. Durejko, M. Polanski, T. Plocinski, W. Zielinski, M. Lazinska, et al., "The microstructure, mechanical properties and corrosion resistance of 316L Stainless steel fabricated using laser engineered net shaping", Materials Science \& Engineering A, 2016, pp. 1-10.

[2] M. Ma, Z. Wang, X. Zeng, "A comparison on metallurgical behaviors of $316 \mathrm{~L}$ stainless steel by selective laser melting and laser cladding deposition", Materials science \& Engineering A, 2017, pp. 265-273.

[3] Y. Zhang, L.E. Rannar, L. Liu, K. Andrey, S. Wikman, J. Olsen, et al, "Additive manufacturing of 316L stainless steel by electron beam melting for nuclear fusion applications", Journal of nuclear materials, 2017, pp. 234-245.

[4] J. Yu, M. Rombouts, G. Maes, "Cracking behavior and mechanical properties of the austentitec stainless steel parts produced by laser metal deposition", Materials \& Design, 2013, pp.228-235.

[5] Y. Zhang, F. Liu, J. Chen, Y. Yuan, "Effects of surface quality on corrosion resistance of $316 \mathrm{~L}$ stainless steel parts manufactured via SLM", Journal of Laser Applications, 29, 022306, 2017.

[6] S.M. Yusuf, Y. Chen, R. Boardman, Y. Shoufeng, N. Gao, "Investigation on porosity and microhardness of 316L stainless steel fabricated by selective laser melting", Metals, 7, 64, 2017.

[7] J.R. Trelewicz, G.P. Halada, O.K. Donaldson, G. Manogharan, "Microstructure and corrosion resistance of laser additively manufactured 316L stainless steel”, The minerals, Metals \& Materials society, 2016.

[8] B.A. Almangour, "Additive manufacturing of high-performance 316L stainless steel nanocomposites via selective laser melting", $\mathrm{PhD}$ thesis, UCLA, 2017.

[9] X. Lou, M.A. Othon, R.B. Rebak, "Corrosion fatigue crack growth of laser additively- manufactured 316L stainless steel in high temperature", Corrosion science, 2017, pp. 120-130.

[10] P. Ganesh, R. Giri, R. Kaul, P.R. Sankar, P. Tiwari, et al., "Studies on pitting corrosion and sensitization in laser rapid manufactured specimens of type 316 L stainless steel”, Materials \& Design, 2012, pp. 509-521.

[11] G. Sander, S. Thomas, V. Cruz, M. Jurg, N. Birbilis, et al., "On the corrosion and metstable pitting characteristics of 316L stainless steel produced by selective laser melting", Journal of the electrochemical society, 2017, pp. 250-257, 2017. 